\title{
Possibility of Using Wind and Solar Sources for Electric Power Generation on Serbian Opencast Coal Mines ${ }^{\dagger}$
}

\author{
Natalija Pavlovic*, Dragan Ignjatovic and Tomislav Subaranovic \\ Faculty of Mining and Geology, University of Belgrade, Djusina 7, 11000 Belgrade, Serbia; \\ dragan.ignjatovic@rgf.bg.ac.rs (D.I.); tomislav.subaranovic@rgf.bg.ac.rs (T.S.) \\ * Correspondence: natalija.pavlovic@rgf.rs \\ † Presented at the International Conference on Raw Materials and Circular Economy, Athens, Greece, \\ 5-9 September 2021.
}

check for

updates

Citation: Pavlovic, N.; Ignjatovic, D.; Subaranovic, T. Possibility of Using Wind and Solar Sources for Electric Power Generation on Serbian Opencast Coal Mines. Mater. Proc. 2021, 5, 50. https://doi.org/ 10.3390/materproc2021005050

Academic Editor: Evangelos Tzamos

Published: 1 December 2021

Publisher's Note: MDPI stays neutral with regard to jurisdictional claims in published maps and institutional affiliations.

Copyright: (c) 2021 by the authors. Licensee MDPI, Basel, Switzerland. This article is an open access article distributed under the terms and conditions of the Creative Commons Attribution (CC BY) license (https:// creativecommons.org/licenses/by/ $4.0 /)$.

\begin{abstract}
The rapid technology advancement and the significant decline of investment costs in wind and solar energy generation have opened up a significant opportunity to build these facilities on closed opencast mines or mines in the phase of closure around the world, where large available areas are almost ideal for such projects. In that sense, it is necessary to give an analysis of the possible application of wind and/or solar energy production in the Republic of Serbia's mines, as well as the dynamics of such a generally ambitious and long-term project with conceptual solutions.
\end{abstract}

Keywords: coal basins; opencast mines; planning process; rehabilitation; wind farm; solar farm

\section{Introduction}

Remediation can repurpose the mine area for useful utility. The increased need for energy generation shows that it is important to examine every potential energy source economically and ecologically. The large areas of opencast mines and their internal and external dumps are ideal for wind or solar farms in certain phases of mining or after closure as the remediation goal.

This research deals with examining the potential of wind and solar farms on the Republic of Serbia's opencast coal mines.

\section{Materials and Methods}

As opencast mine closure with the internal and external dumps is a time-consuming process, it is necessary to constantly re-examine the dynamics and types of remediation over a large area [1-4] after geomechanical stabilization. The basin area can be used alone or in combination with a domain of energy generation (wind, sun, geothermal, and biomass) and the usage of anthropogenic reserves, as well as in the fields of agriculture, tourism, recreation, and various types of industry. The complete remediation process with the possibility of using the area after the completion of opencast coal mining and the analysis of the existing situation from the political, economic, social, and technological perspectives (PEST), as well as SWOT and risk analyses, is shown in Figure 1 [4].

The areas of closed mines on many opencast coal mines around the world have been used for agriculture, tourism, recreation, and industry for decades through a series of good, but very expensive, projects [5,6]. Projects for using the space on internal and external dumps for energy generation are still at the start of implementation, both in terms of technical solutions and in terms of economic justification.

Before making a decision, it is necessary to make prefeasibility and feasibility studies with a risk analysis in order to fully prove the justification of considerable investments in renewable energy sources in terms of meeting the principles of sustainable mining. 


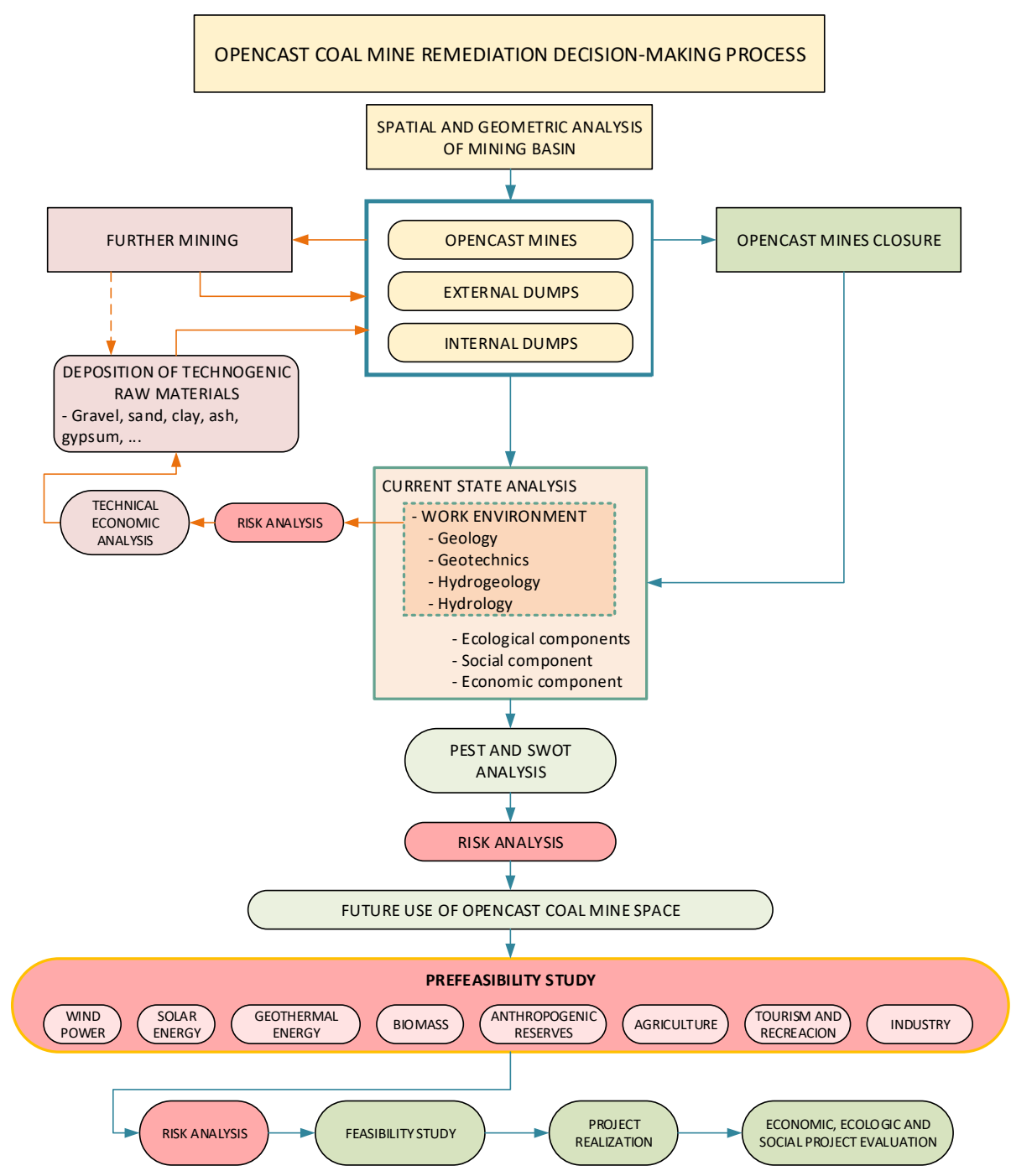

Figure 1. The process of remediation with possible use of opencast closed mine space in coal basins.

ECOFYS mapping for neighboring Southeastern European (SEE) Member States from 2017 can be used to analyze the possibility of using renewable energy sources on Serbia's coal basins [7]. This mapping showed that the optimized Leveled Cost of Electricity (LCOE) for wind is about $80 \mathrm{EUR} / \mathrm{MWh}$ with around 2500 full load hours, while for solar it is about 140 EUR/MWh with around 1100 full load hours.

It is significant to note that the capital and operating costs for wind and solar power generation technologies are constantly declining (over $25 \%$ for wind and over 50\% for solar energy in the last few years), which puts them in an increasingly favorable position compared to other projects based on fossil primary energy (Figure 2).

On the other hand, when it comes to wind and solar power plants, there is a very serious environmental and economic issue of waste disposal which has not been seriously calculated so far and is becoming a significant technological risk. Moreover, the construction of solar and wind power plants requires an extreme quantity of critical metals (Figure 2). Therefore, the risks related to the prices of critical metals are becoming more noticeable because the prices are constantly growing due to the high demand. It is very possible, with the high price of electricity in mind, that the development in this area will be socially and economically critical. 


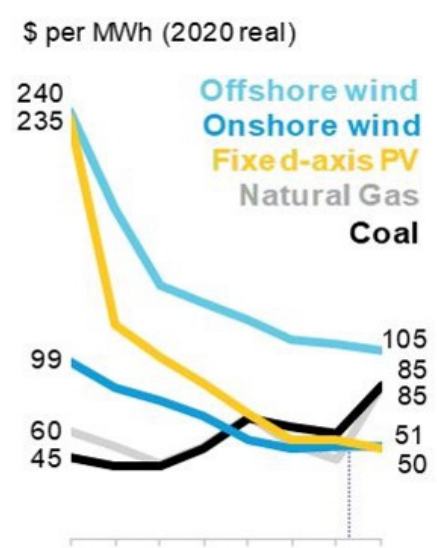

$14151617 \quad 18192021$

\begin{tabular}{lllllllll} 
kg/MW & Copper & Nickel & Manganese & Cobalt & Chromium & Molybdenum & Zinc & $\begin{array}{l}\text { Rare } \\
\text { earths }\end{array}$ \\
$\begin{array}{l}\text { Offshore } \\
\text { wind }\end{array}$ & 8.000 & 240 & 790 & 0 & 525 & 109 & 5.500 & 239 \\
\hline $\begin{array}{l}\text { Onshore } \\
\text { wind }\end{array}$ & 2.900 & 404 & 780 & 0 & 470 & 99 & 5.500 & 14 \\
\hline Solar PV & 2.822 & 1.3 & 0 & 0 & 0 & 0 & 30 & 0 \\
\hline Nuclear & 1.473 & 1297 & 148 & 0 & 2.190 & 70 & 0 & 0.5 \\
\hline Coal & 1.150 & 721 & 4.63 & 201 & 308 & 66 & 0 & 0 \\
\hline Natural gas & 1.100 & 16 & 0 & 1.8 & 48.34 & 0 & 0 & 0 \\
\hline Source: IEA & & & & & & & &
\end{tabular}

(b)

Figure 2. (a) LCOE for new solar and wind versus the running cost of existing coal- and gas-fired power plants in Germany, 2014-2021 (BloombergNEF); (b) minerals used in clean energy technologies compared to other power generation sources (IEA, 2021).

\section{Results}

\subsection{Wind and Solar Energy Possibilities on Opencast coal Basins Kostolac and Kolubara}

There are two large coal basins in Serbia (Kolubara and Kostolac) in which intensive opencast mining is carried out.

According to the data [8], it is noticeable that the wind suitability area of the Kostolac coal region is more favorable, with a range of $586 \mathrm{~W} / \mathrm{m}^{2}$ for a $10 \%$ wind area and with about $400 \mathrm{~W} / \mathrm{m}^{2}$ for a $100 \%$ wind area, compared to the Kolubara coal region with a range of $255 \mathrm{~W} / \mathrm{m}^{2}$ for a $10 \%$ wind area and about $200 \mathrm{~W} / \mathrm{m}^{2}$ for a $100 \%$ wind area (Figure 3 ).

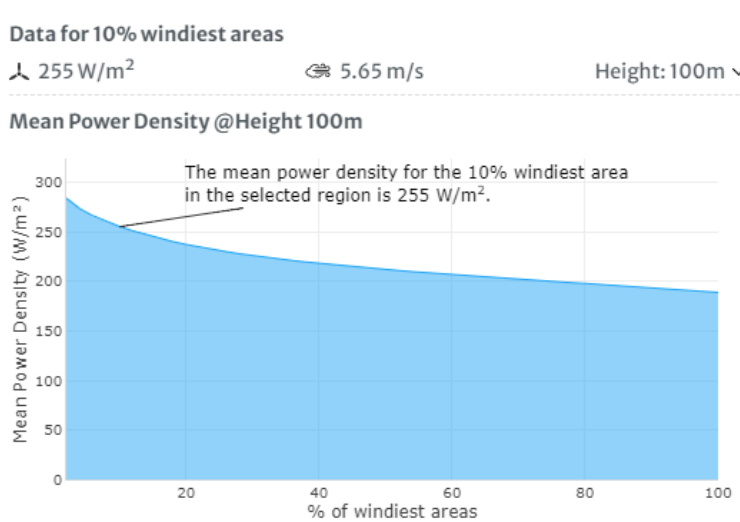

(a)

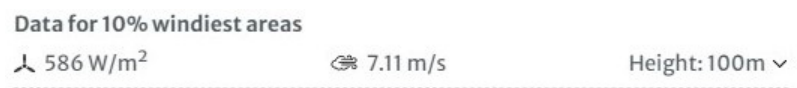

Mean Power Density @Height 100m

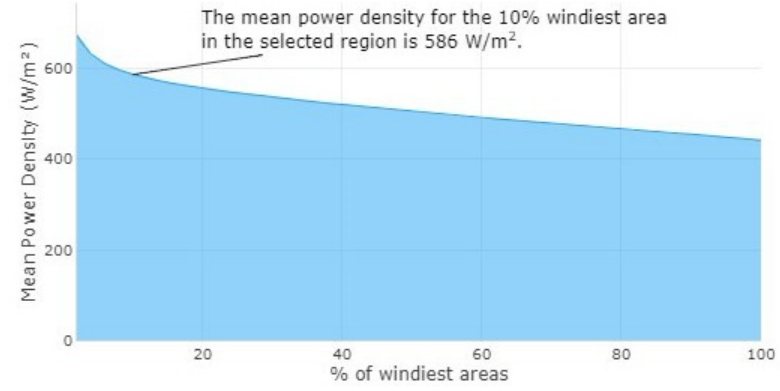

(b)

Figure 3. Wind power density of the Kolubara (a) and Kostolac (b) coal basins areas.

Wind power density and the achieved geomechanical stability on the internal and external dumps of the closed Kostolac opencast mines, which are over 30 years old, indicate the real possibility of forming wind parks with 20 wind turbines and a total power of about $60 \mathrm{MW}$ [4]. The preparation of the Feasibility Study is in progress in accordance with the set remediation decision process (Figure 1). In the case of positive results, the development of wind parks is planned for 2025. There are no realistically justified technical (geomechanical characteristics of the material and potential for the occurrence of liquefaction) and natural possibilities for the formation of wind parks in the foreseeable future on the un-stabilized dumps of the Kolubara coal basin. 
According to the data [9], it is noticeable that the specific photovoltaic power output in the regions of both the Kolubara and the Kostolac coal basins is almost equal to a PVOUT of about $3.5 \mathrm{kWh} / \mathrm{kWp}$ and has the global tilted irradiation (GTI) of about $4.3 \mathrm{kWh} / \mathrm{m}^{2}$ (Figures 4 and 5). The natural and technical conditions to launch an initiative for the formation of solar parks in the stabilized area of external and internal dumps are favorable.

\begin{tabular}{l} 
Map data (min-max range) \\
Specific photovoltaic power \\
output \\
Direct normal irradiation \\
Global horizontal irradiation \\
\hline Diffuse horizontal irradiation \\
Global tilted irradiation \\
\hline Optimum tilt of PV modules \\
Air temperature \\
\hline Terrain elevation
\end{tabular}

\begin{tabular}{|c|c|c|c|c|}
\hline PVOUT & $3.49-$ & 3.52 & $\mathrm{kWh} / \mathrm{kWp}$ & \\
\hline DNI & $3.34-$ & 3.39 & $\mathrm{kWh} / \mathrm{m}^{2-}$ & \\
\hline GHI & $3.67-$ & 3.69 & $\mathrm{kWh} / \mathrm{m}^{2}=$ & \\
\hline DIF & $1.70-$ & 1.72 & $\mathrm{kWh} / \mathrm{m}^{2-}$ & \\
\hline GTI & $4.24-$ & 4.28 & $\mathrm{kWh} / \mathrm{m}^{2-}$ & \\
\hline OPTA & $34-$ & 35 & 。 & \\
\hline TEMP & $12.1-$ & 12.9 & ${ }^{*} \mathrm{C}^{-}$ & \\
\hline ELE & $39-$ & 344 & $\mathrm{~m}^{*}$ & \\
\hline
\end{tabular}

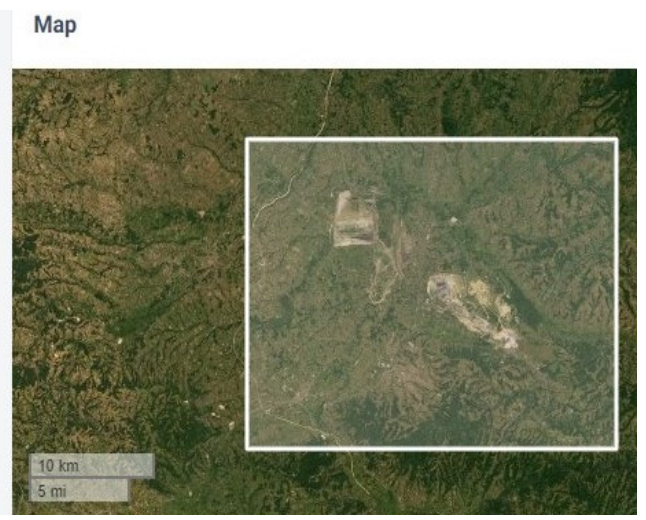

Figure 4. Coal basin Kolubara west (available flat surface 1900 ha) and east opencast mine area photovoltaic possibilities (available flat surface 1700 ha) (data obtained from the "Global Solar Atlas 2.0, a free, web-based application is developed and operated by the company Solargis s.r.o. on behalf of the World Bank Group, utilizing Solargis data, with funding provided by the Energy Sector Management Assistance Program (ESMAP). For additional information: https://globalsolaratlas.info) [9].

\begin{tabular}{|c|c|c|c|c|}
\hline Map data (min-max range) & & & & Per day \\
\hline $\begin{array}{l}\text { Specific photovoltaic power } \\
\text { output }\end{array}$ & PVOUT & $3.47-$ & 3.54 & $\mathrm{kWh} / \mathrm{kWp}$ \\
\hline Direct normal irradiation & DNI & $3.30-$ & 3.40 & $\mathrm{kWh} / \mathrm{m}^{2-}$ \\
\hline Global horizontal irradiation & GHI & $3.65-$ & 3.71 & $\mathrm{kWh} / \mathrm{m}^{2}=$ \\
\hline Diffuse horizontal irradiation & DIF & $1.70-$ & 1.72 & $\mathrm{kWh} / \mathrm{m}^{2}=$ \\
\hline Global tilted irradiation & GTI & $4.21-$ & 4.30 & $\mathrm{kWh} / \mathrm{m}^{2-}$ \\
\hline Optimum tilt of PV modules & OPTA & $33-$ & 35 & $\cdot$ \\
\hline Air temperature & TEMP & $12.4-$ & 12.9 & ${ }^{\circ} \mathrm{C}^{-}$ \\
\hline Terrain elevation & ELE & $36-$ & 287 & $\mathrm{~m}^{2}$ \\
\hline
\end{tabular}

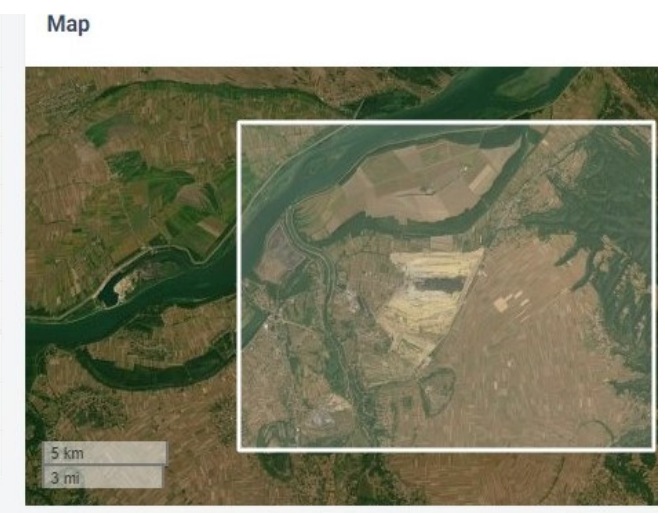

Figure 5. Coal basin Kostolac opencast mine Drmno area photovoltaic possibilities (available flat surface 1800 ha) (data obtained from the "Global Solar Atlas 2.0, a free, web-based application is developed and operated by the company Solargis s.r.o. on behalf of the World Bank Group, utilizing Solargis data, with funding provided by the Energy Sector Management Assistance Program (ESMAP). For additional information: https://globalsolaratlas.info) [9].

\subsection{Opencast Coal Mine Solar Energy use Preliminary Conception}

In the world, especially in the EU, the implementation of the plan to achieve zero greenhouse gas emissions by 2050 is underway. In that sense, the use of the space of the Kostolac and Kolubara coal basins for renewable energy sources was considered with the planned mine development and closure of the opencast mines by 2050.

The flat, i.e., the slightly sloping surface of the internal dumps of the Tamnava-West Field, East Field, and Radljevo opencast mines in the western part of the Kolubara Basin is about 1900 ha.

The available area for the construction of the solar park is about 1100 ha. It is possible to build a solar park with a total of about $275 \mathrm{MW}$ of installed capacity in the next 30 years (Table 1). 
Table 1. Dynamics of using opencast mine flat surfaces (ha).

\begin{tabular}{cccccc}
\hline Location & MW/PV Area, ha & $\mathbf{2 0 2 5}$ (ha) & $\mathbf{2 0 3 0}$ (ha) & 2040 (ha) & 2050 (ha) \\
\hline Kostolac coal basin-Drmno & $250 / 1000$ & 40 & 160 & 300 & 500 \\
\hline Kolubara coal basin-West Part & $275 / 1100$ & - & 200 & 400 & 300 \\
\hline Kolubara coal basin-East Part & $200 / 800$ & - & 100 & 460 & 1000 \\
\hline Total (ha) & 2900 & 40 & 115 & 250 & 300 \\
\hline Planned Installed Capacity (MW) & 725 & 10 & & 350 \\
\hline
\end{tabular}

The slightly sloping surface of the internal dumps in the eastern part of the Kolubara basin is about 1700 ha. The available area for the construction of a solar park is about $800 \mathrm{ha}$. It is possible to build a solar park with a total of about $200 \mathrm{MW}$ of installed capacity in the next 30 years (Table 1 ).

The internal dump of the Drmno opencast mine in the Kostolac basin will have about 1800 ha of flat and slightly sloping surface by 2050 . The available area for the construction of a solar park will be about $1000 \mathrm{ha}$. It is possible to build a solar park with a total of about 250 MW of installed capacity in the next 30 years (Table 1).

The necessary space for communications, auxiliary facilities, and geomechanical safety zones were subtracted from the calculation of the available areas. It was established that for $1 \mathrm{MW}$ of PV panels of installed power an average of about 4 ha is needed for a ground solar park.

The preliminary planned dynamics of the construction of ground solar parks on the internal dumps of Kostolac and Kolubara coal basins are given in Table 1.

\section{Discussion}

The risk of the project realization in using the surfaces of external and internal dumps for the formation of wind and solar farms for electric power generation is the possibility of events that may adversely affect the achievement of the set company goal. As a starting point for the risk analysis, the preliminary results of the PEST and SWOT analyses were taken, after which the types of potential risks were defined.

Analysis of all the risks, especially the financial risks, is necessary for each project. Investment risks in energy from renewable sources (RE) is of particular importance, primarily due to the changing legislation in this area, the strategic planning on a national level, and the stability of the country. As the total cost of capital, expressed as the weighted average cost of capital (WACC), is paid out of the project revenue, its increase entails higher risks. In addition, the implementer of investments in energy facilities has limited opportunities to change the cost budget due to changes in economic conditions. Therefore, the essential policy of supporting investments in energy from renewable sources is to provide as much security as possible in relation to the costs and revenues of the project. A study sensitivity analysis of the impact of WACC solar energy on LCOE shows an increase in LCOE from $100 \%$ to $200 \%$ if the WACC project increases by only $5 \%$ to $10 \%$ [4].

In addition to the financial risks, the technological risks are also very relevant. These include possible investments related to new technologies, connection to existing grid infrastructure and permitting procedures, grid access, site selection and preparation, energy storage, standards for design, construction and use of facilities and equipment for production, transformation, transmission and distribution of electricity, etc.

Environmental risks are associated with the increasing use of critical raw materials, waste disposal with exponential growth, aesthetic criteria, wildlife habitat protection and noise pollution due to wind turbines, and the ban on the installation of wind turbines depending on the distance from settlements.

For now, in most SEE countries (Serbia, BiH, N. Macedonia, Montenegro, and Slovenia) investments in energy from renewable sources are made by state mining and energy companies with a reduced, relatively high investment risk and an unstable regulatory framework, with a simplified connection to the electricity network. 
The traditional qualitative approach to risk assessment was used for the preliminary analysis, which is based on a five-range matrix. From the aspect of EPS investments in PV ground solar parks, on a scale from 1 to 25 , it is estimated as economic risks-Low medium 4, technological—Low medium 3, Environmental-Low 2, and Social-Low 1. The approach should be sustainable as a partial replacement of electric power generation from coal with renewable energy in line with the planned dynamics of TPP shutdown. For EPS, the total risk of project implementation as a sum of mutually independent risks is 10 and represents a generally acceptable medium risk, so it can be recommended to the company to prepare a feasibility study along with further activities on the final remediation, which would confirm the justification of investing in ground solar farms.

\section{Conclusions}

The realization of the set process of opencast coal mine remediation achieves satisfying effects on the environment. Mining closure projects need to constantly adapt to possible strategic alterations with constant monitoring of the probabilities of risk occurrence due to dangers to the environment and community interests. The need to achieve the UN targets for zero emission by 2050 strongly encourages appropriate approaches to the remediation of closed mines or phased out dumps in developing mines.

The external and internal dumps of the Kolubara and Kostolac coal mines cover large flat or slightly sloping areas, which are potentially suitable for the formation and construction of wind and ground solar farms for electric power generation. The stabilized dumps of the Kostolac Basin are over 30 years old, which makes them suitable for wind farms with a capacity of about $60 \mathrm{MW}$, considering the favorable natural conditions of wind strength and intensity. The phase formation of ground solar farms is proposed for other areas on all opencast mines, taking geomechanical stability and weather conditions into account. It has been preliminarily proven that in 30 years, according to the mining development dynamics, ground solar plants with a capacity of about $725 \mathrm{MW}$ can be built on a total area of about 2900 ha.

The preliminary results of the risk analysis showed that the state-owned company Electric Power Industry of Serbia can initiate further activities on the implementation of such a project with acceptable risks, applying the accepted process of remediation according to the principles of sustainable mining in accordance with state strategies of energy development.

\section{References}

1. International Council on Mining and Metals. Integrated Mine Closure, Good Practice Guide, 2nd ed.; ICMM: London, UK.

2. Pavlovic, V. Reclamation of Opencast Mines, 1st ed.; Faculty of Mining and Geology, University of Belgrade: Belgrade, Serbia, 2002.

3. Pavlovic, V.; Subaranovic, T. Mines Closure Strategy. Podzemni Radovi. 2012. Available online: http://ume.rgf.bg.ac.rs/index. $\mathrm{php} / \mathrm{ume} /$ article/view/82 (accessed on 3 June 2021).

4. Subaranovic, T.; Ristovic, I.; Pavlovic, N. Sustainable Long-term Planning of the Kostolac Coal Basin Opencast Mines Closure. In Proceedings of the 12th International Conference on Mine Closure, Leipzig, Germany, 3-7 September 2018; pp. 265-280.

5. Drebenstedt, C.; Kuyumcu, M. Braunkohlesanierung, 1st ed.; Drebenstedt, C., Kuyumcu, M., Eds.; Springer: Berlin/Heidelberg, Germany, 2014.

6. Government of Western Australia, Department of Mines, Industry Regulation and Safety. Mine Closure Plan Guidance, 3rd ed.; Government of Western Australia, Department of Mines, Industry Regulation and Safety: East Perth, Australia, 2020.

7. Wignad, F.; Dukan, M. Mapping the Cost of Capital for Solar and Wind Energy in South Eastern European Countries. Findings from the Pricetag Project; ECOFYS Netherlands B.V.: Utrecht, The Netherlands, 2017.

8. Global Wind Atlas. Available online: https://globalwindatlas.info/ (accessed on 3 June 2021).

9. Global Solar Atlas. Available online: https:/ / globalsolaratlas.info/map?c=11.609193,8.261719,3 (accessed on 3 June 2021). 